19 Revue d'histoire du XIXe siècle

Société d'histoire de la révolution de 1848 et des

révolutions du XIXe siècle

24 | 2002

Varia

\title{
Michèle RIOT-SARCEY, Thomas BOUCHET et Antoine PICON [dir.], Dictionnaire des Utopies
}

Paris, Éditions Larousse, 2002, 284 p.

Louis Hincker

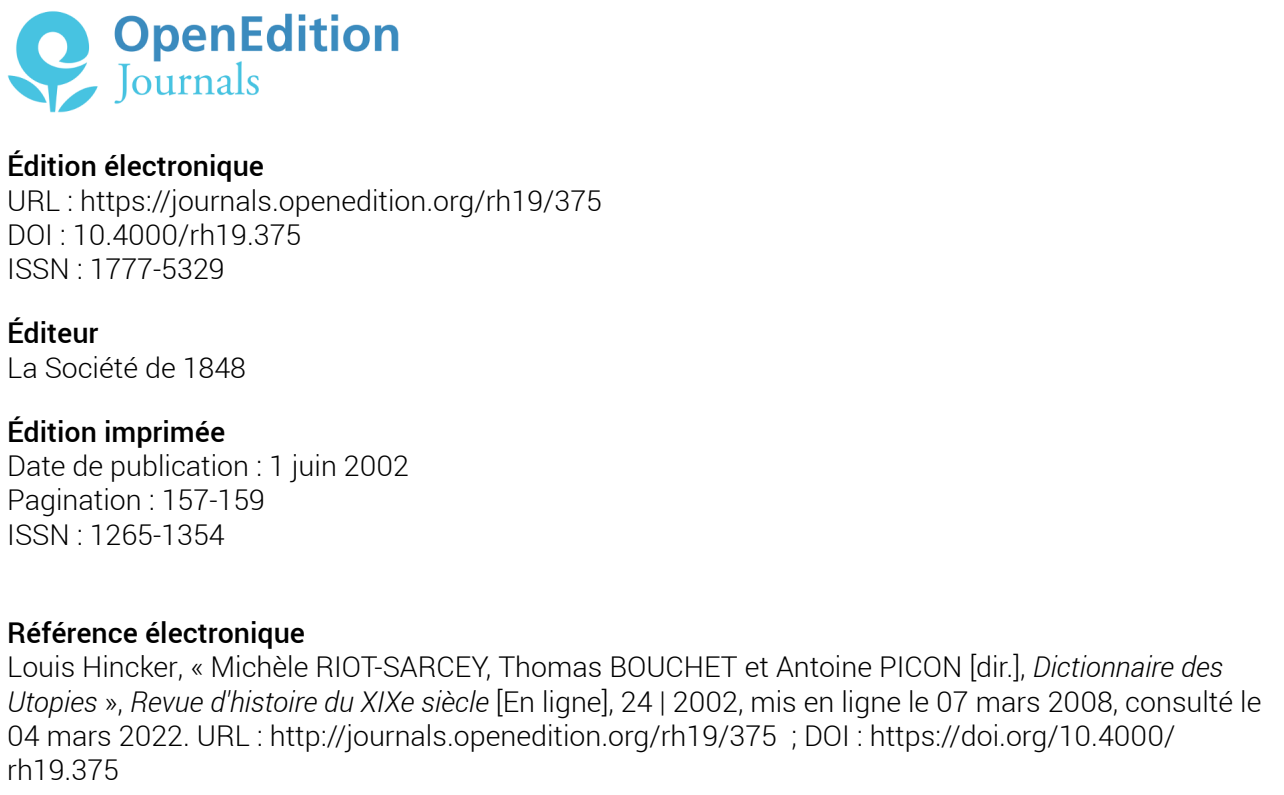

Ce document a été généré automatiquement le 4 mars 2022.

Tous droits réservés 


\section{Michèle RIOT-SARCEY, Thomas BOUCHET et Antoine PICON [dir.], Dictionnaire des Utopies}

Paris, Éditions Larousse, 2002, 284 p.

\section{Louis Hincker}

\section{RÉFÉRENCE}

Michèle RIOT-SARCEY, Thomas BOUCHET et Antoine PICON [dir.], Dictionnaire des Utopies, Paris, Éditions Larousse, 2002, 284 p.

1 Pas de définition univoque dans ce bel ouvrage collectif, ni de grande fresque, mais un dictionnaire pour signifier la pluralité et la diversité, et le lecteur est invité à voyager, à vagabonder, de l'Antiquité à nos jours, pour visiter les dimensions, ou mieux, les ambitions utopiques de la fiction, du théâtre, de la musique, de l'art et de l'architecture, des sciences et des techniques, du corps et de la poésie, de la politique aussi. Le Dictionnaire des Utopies, tout en proposant des synthèses plus attendues sur tel ou tel auteur, tel ou tel courant de pensée, étend très loin le domaine de la réflexion sur ce qui apparait au fil de la centaine d'articles - compléments bibliographiques à l'appui -, rédigés par quelques 70 collaborateurs, moins un objet en tant que tel qu'une fonction à part entière. Car la démarche générale est historienne. Toutes les utopies s'inscrivent dans le présent de leur énonciation et de leur réalisation, nous est-il expliqué. Inclassables, à l'écart de l'ordre dominant, elles disent d'autres mondes possibles, elles établissent d'autres liens entre idéal et réel. Elles sont aussi très concrètement réprimées, reléguées peu à peu dans un passé oublié. Le statut de fait historique leur est dénié.

2 Un utile Thesaurus révèle que près d'une quarantaine d'entrées du dictionnaire concernent directement le XIX ${ }^{e}$ siècle. La période est donc valorisée pour spécifier l'esprit utopique qui se développe alors, signe d'un moment théorique particulier : il 
n'y aurait d'utopie que d'utopie politique, et les anticipations, jusqu'à l'excès de mots, qu'elles produisent ont une fonction critique, ouvertement conflictuelle, ici et maintenant. Le dictionnaire égraine les procès en utopie qui à l'époque dénient toute légitimité historique à la multitude de projets qui proposent de nouvelles manières d'être, qui envisagent l'avènement d'un homme nouveau, d'un autre système social, d'un autre monde moral, d'une nouvelle science, d'une religion sans dieu. Paradoxalement, ces visées réformatrices se veulent parfois apolitiques, car le radicalisme des critiques qu'elles adressent aux institutions - le fameux «écart absolu » de Fourier, maitre mot du dictionnaire - qui leurs sont contemporaines les amènent à rechercher dans les lois naturelles le modèle de société auquel elles aspirent, jusqu'à éluder les questions de pouvoir et de gouvernement, remplacées par un idéal de vie réglée, jusqu'à taxer d'«utopiques» les anticipations qui leur paraissent trop concurrentes ! Car la pluralité est loin d'être harmonieuse.

Cependant le dictionnaire dit bien l'unification conceptuelle préalable qui permet l'émergence au XIX siècle des utopies techniciennes et économiques à la veine prométhéenne. L'apologie des facultés productives de l'homme conçoit l'intervention comme le moteur de l'émancipation. Seront vaincues les luttes désordonnées et artificielles, balayées les injustices et les inégalités, reconnus les droits naturels, réalisée l'Association spontanée et harmonieuse, révélée l'humanité à elle-même, conciliés l'individuel et le collectif, advenue la nouvelle science sociale, disparues les classes sociales, libérées les femmes. Les projets définissent des pratiques utopiques qui doivent rendre concrètes toutes ses attentes autant accessibles que contrariées.

4 En attendant, les expériences communautaires profitent surtout des espaces américains, cependant que dans le vieux monde, dans la France de la monarchie de Juillet notamment, sur une possible "réforme sociale» s'opposent "doctrinaires libéraux» et "utopistes socialistes». La Révolution française a légué autant de problèmes en suspens que de solutions. Quelle réalité attribuée à une catégorie comme la "liberté »? Y a-t-il un seuil qui rende les distinctions sociales acceptables? La démocratie représentative améliore-t-elle les rapports sociaux? Il y a des écrits, des inventions technologiques, des événements, des individus, des groupes, des solidarités, qui signifient la réalité pour la dépasser. Le dictionnaire parle de certaines d'entre elles pour le XIX ${ }^{e}$ siècle : grève générale, réseaux de transport, maison de verre, révolution, etc. Il ne met pas de borne chronologique à la réalité des utopies, ni à la possibilité d'en faire l'histoire. 